\title{
Hacia una política de la documentación artística y la gestión de los archivos
}

Towards a Policy of Art Documentation and Archive Management

\author{
Christian Alberto Gómez Vega \\ Facultad de Ciencias Políticas y Sociales (FCPys), \\ Universidad Nacional Autónoma de México (UNAM), México \\ gomez.christian@outlook.com
}

\section{Resumen}

La presente contribución plantea una doble problemática sobre la documentación y generación de los archivos de prácticas artísticas contemporáneas: a la par que llama la atención sobre su importancia para generar investigación y difusión, subraya algunos retos que los archivos resultantes plantean en relación con su materialidad ante la falta de protocolos en la materia y las implicaciones políticas de tal deficiencia. El ENSAYO cruza referencias teóricas y entrevistas con responsables en la materia en el Museo Universitario Arte Contemporáneo (MUAC), Universidad Nacional Autónoma de México (UNAM), Laboratorio Arte Alameda (LAA) y el archivo conformado por el dueto artístico Pinto mi Raya, todos en México.

\section{Palabras clave}

documentación; arte contemporáneo; gestión de archivos; prácticas artísticas

\section{Abstract}

This paper poses a twofold problem concerning the documentation and archiving process of contemporary art practices. On one hand, this contribution stresses the importance of archiving practices for research and dissemination purposes and, on the other hand, it shows the challenges the archives are facing because of a lack of knowledge and protocol on their material aspects and due to the political implications caused by such shortcomings. This ESSAY combines referential theories and interviews conducted with those agents (curators and conservators) in charge of the subject matter, all from the Museo Universitario de Arte Contemporáneo (MUAC, The University Museum of Contemporary Art), Universidad Autónoma de México (UNAM, The National Autonomous University of Mexico), Laboratorio Arte Alameda (LAA, The Alameda Art Laboratory) and the archive of the artistic duet Pinto mi Raya, all in México.

Key words

documentation; contemporary art; archive file management; artistic practices 


\section{Introducción}

os artistas visuales que durante la primera mitad del siglo XX desbordaron el canon modernista de la producción artística y llevaron sus prácticas, más allá de la pintura y la escultura, hacia la inmaterialidad o hacia una multiplicidad de materiales nunca antes vista (Gordon 2013:1-4), ${ }^{1}$ formularon nuevos cuestionamientos para la historia del arte y de disciplinas afines. El hecho de que el cuerpo de los artistas pudiera ser el soporte de las obras, como en los happenings o las performances, que un gesto permitiera elevar cualquier objeto al estatus artístico como en el ready-made, o que la construcción de una situación ${ }^{2}$ para alterar el orden cotidiano constituyera en sí las formas de existencia de la obra de arte redundó en un giro irreversible en términos materiales ${ }^{3} y$ de escritura de la historia. ¿Cómo dar cuenta o problematizar una obra que no permanece en el tiempo, sino que supone una duración no sólo breve sino irrepetible? ¿De qué manera los nuevos públicos e investigadores pueden aproximarse a obras intencionalmente efímeras, esto es, concebidas para desaparecer? ¿Cuál es el papel de los museos en la preservación de obras efímeras o performativas?

En su investigación sobre el proceso comunicativo, emprendida desde la década de 1960, el artista estadounidense James Lee Byars (1932-1997) exploró las relaciones epistolares, la legibilidad e ilegibilidad en la escritura y la carga significativa de los materiales utilizados en sus obras (Arriola y Eleey 2014), no obstante lo cual fue en una performance, La carta de amor perfecta es escribir

\footnotetext{
${ }^{1}$ En su artículo, (2013:1) formula un cuestionamiento acerca de la manera en que se han expandido las prácticas artísticas en términos materiales. Con base en un panorama histórico que va del ready-made y pasa por el "todo y nada puede ser material" en el arte que Allan Kaprow enunció en 1958, supone una pregunta fascinante: "With this democratisation of choice and adoption of ephemeral materials, comes a dilemma for those charged with giving the artwork a future: how do we determine the artwork's materials and their role in the identity of the work?".

${ }^{2}$ La "construcción de situaciones" fue una estrategia del movimiento situacionista, en el que coincidieron artistas y militantes políticos entre 1957 y 1972. Su objeto consistía en alterar el orden cotidiano para producir en los ciudadanos de a pie una reflexión sobre los efectos de la alienación en la "sociedad del espectáculo". Al respecto puede consultarse el libro La sociedad del espectáculo (Debord 1967). Por otra parte, si bien no identificados como situacionistas, los integrantes del colectivo GRAV trabajaron también en Francia a partir de la construcción de situaciones con objetivos críticos y políticos. Curada por Andrea Torreblanca, la muestra de su trabajo Una visión otra: Groupe de Recherche d'Art Visuel, 1960-1968 se presentó en el Museo Tamayo del 7 de septiembre del 2013 al 9 de febrero del 2014.

${ }^{3}$ Sólo por mencionar un ejemplo, Ilama la atención la manera en que, en su emblemático artículo de 1979 para la revista October, la crítica de arte Rosalind Krauss (Krauss 1996:59-74) introdujo su planteamiento con el siguiente comentario: "en los últimos 10 años, una serie de cosas bastante sorprendentes han recibido el nombre de esculturas".
}

"te quiero" en el aire y al revés, de 1974, donde encontró un momento cumbre de ese proceso de investigación: lo hizo, literalmente, al escribir un mensaje en el aire que, desde luego, no tenía la posibilidad de quedar fijado. Obra que consistió en ese gesto efímero que evidenciaba la imposibilidad de inscripción y, por lo tanto, de la lectura del mensaje, a la que hoy conocemos por los registros fotográficos y el contexto con el que se acompañan. Por citar otro ejemplo, en sus indagaciones sobre las estructuras del pensamiento en su relación con la colectividad reunió a grupos de personas que utilizaban vestuarios colectivos - un sombrero para dos o un vestido para cuatro- con la finalidad de examinar los efectos de la proximidad en dichas circunstancias. De aquellas obras, basadas en la experiencia, se conservan los fragmentos de tela que el artista entregaba a los participantes (Arriola y Eleey 2014). Este tipo de prácticas artísticas plantea, tanto desde el punto de vista de la historia del arte como desde el papel de las instituciones museísticas, múltiples inquietudes: ¿qué tipo de huellas de la experiencia artística constituyen estos vestigios y cuál es su función en las exhibiciones o en las colecciones? ¿Cómo explicarnos su condición, cifrada en la tensión entre fungir como documento y pasar por la obra misma, aunque sean apenas su registro o vestigio?

Así, ante los problemas que suscita este género de prácticas artísticas contemporáneas, desde las performativas y las no objetuales hasta aquellas que confirman que cualquier tipo de materiales puede integrar las obras (Gordon 2013:1-4), el presente ensayo nace del cruce de dos planteamientos de conservadores de arte mexicanos que se ocupan de la documentación de prácticas artísticas contemporáneas, la gestión de los archivos así generados y la reactivación de obras. El primero, de Claudio Hernández, actual responsable del Departamento de Conservación y Restauración del Museo Universitario Arte Contemporáneo (MUAC) de la Universidad Nacional Autónoma de México (UNAM, México), quien en su tesis de licenciatura (Hernández 2005) ofreció una propuesta de conservación para el acervo documental del Laboratorio Arte Alameda (LAA, Instituto Nacional de Bellas artes [INBA], MéxiCo), el espacio más visible en nuestro país para las artes de los "nuevos medios"; el segundo, de Jo Ana Morfín, para quien la documentación de obras debería concebirse para permitir su recreación, en el entendido de que ningún documento sustituye la experiencia estética. ${ }^{4}$ Las posturas de ambos conservadores, quienes han teorizado sobre modelos de documentación de las prácticas artísticas contemporáneas de los nuevos medios y efímeras,

\footnotetext{
${ }^{4}$ El planteamiento forma parte de la investigación doctoral inédita de Morfín. Una parte de su argumento, el referido en este ensayo, fue presentado durante su visita, el 25 de abril del 2014, al Seminario Arte y Materialidad del posgrado en historia del arte de la UNAM, impartido por la maestra Sandra Zetina Ocaña en el Instituto de Investigaciones Estéticas (IIES).
} 
constituyen, pues, un punto de partida de este ensayo, que, por una parte, busca indagar la naturaleza de estos registros y su gestión y, por la otra, en un segundo nivel, aprovecha la oportunidad para pensar en los usos de los archivos generados por tales documentaciones.

Se presenta, entonces, una doble pregunta que guiará el trabajo: ¿cuáles son las circunstancias actuales de la generación de archivos sobre obras inestables - retomo la idea de Jo Ana Morfín, quien se considera una "conservadora de eventos inestables" -5 y qué reto supone esta tarea para los museos de arte contemporáneo en México? Este cuestionamiento se formula tras el ya mencionado cruce de los planteamientos de Hernández y Morfín, con base, en primer lugar, en la hipótesis de que la generación de una documentación adecuada (que en sí misma supone problemas de conservación material, de accesibilidad y de recuperación de sentido) ofrece la posibilidad de investigar y difundir la producción artística contemporánea inestable $y$, en segundo lugar, en la necesidad de conocer las características específicas para recrear estas obras y generar nuevas experiencias para nuevos públicos. Pensar en este punto, en el que se atraviesan estas circunstancias, permitiría ampliar la perspectiva sobre la valoración del papel de la documentación y la generación de archivos, y, por ende, acerca de su gestión en términos materiales y de recursos.

\section{Ausencias}

En una visita reciente al Centro de Documentación del Museo de Arte Moderno (MAM, México) ${ }^{6}$ intenté consultar los materiales alusivos a Se traspasa. Proyectos nómadas, serie de propuestas de trabajo colaborativo que se han presentado a lo largo de varios años en el pequeño espacio que antes alojara la tienda del museo: de acuerdo con su personal, si bien los curadores son responsables de entregar una carpeta con material documental de cada exposición o proyecto, de Se traspasa no existe mayor registro fotográfico que el de un par de propuestas. Debido a dicha ausencia de registros documentales, quien no haya visitado las muestras no podrá conocer el trabajo que se hizo en el museo para, precisamente, visibilizar tales prácticas artísticas, aparte de que se entorpece un proceso de investigación sobre tal proyecto, como el que pretendía llevar a cabo quien escribe. En la misma visita se buscó una serie de folletos, realizada hace un par de años, en la que, a convocatoria del MAM, diferentes especialistas reflexionaron sobre temáticas del mundo

\footnotetext{
${ }^{5}$ Ante la definición de "medios inestables" debe hacerse notar el papel del proyecto interdisciplinario Capturing Unstable Media que distintas instituciones neerlandesas conformaron durante 2003 para estudiar casos y formular recomendaciones sobre estrategias de documentación y preservación ante prácticas artísticas que involucran tecnología y el cuerpo (V2_lab 2003).

${ }^{6}$ La visita se realizó el 3 de marzo de 2014.
}

del arte (la crítica, perspectivas de los museos, etc.); sin embargo, no se conservan salvo tres títulos (un ejemplar de cada uno) de una serie de al menos ocho. ¿Cómo indagar acerca de esos trabajos?

La ausencia sorprende, pues fue en el MAM donde en 2011 se presentó, con la curaduría de Sol Henaro, la muestra No Grupo. Un zangoloteo al corsé artístico. La exposición consistió en una revisión del trabajo que, entre 1977 y 1983, realizó el colectivo artístico No Grupo, integrado por Melquíades Herrera, Alfredo Núñez, Rubén Valencia y Maris Bustamante (Henaro 2011:11). Contrario a la estructura del mundo del arte, el No Grupo se burló de la fetichización de los objetos artísticos y centró su práctica en una producción "no objetual", ${ }^{7}$ como es el caso de sus montajes de "momentos plásticos" ${ }^{8}$ Entre las lecciones de la investigación realizada por Henaro (2011) para esta exposición, hay que reconocer que ésta fue posible sólo a partir de la revisión y la utilización de los materiales reunidos en los archivos de los artistas (no necesariamente en los de la institución), así como del diálogo entre la curadora y algunos de los miembros del grupo. ${ }^{9}$ Se hace evidente, así, el papel fundamental de las documentaciones y los archivos para aproximarse, investigar, contextualizar y problematizar tales prácticas: a casi tres décadas del trabajo del No Grupo, la revisión Ilamó la atención a propósito de las ausencias de sus obras en las colecciones de los museos. ${ }^{10}$

Pese al conocimiento de experiencias como ésta, en los museos que albergan este tipo de representaciones artísticas existen grandes pendientes que tienen que ver

\footnotetext{
${ }^{7}$ Juan Acha formuló el término no-objetualismos; rescato la cita que se utiliza como presentación del catálogo de la muestra No Grupo. Un zangoloteo al corsé artístico (Henaro 2011:9):

El arte deja de ser un fin en sí mismo y se instaura como un medio, sea de las preocupaciones políticas como de las contraculturales. Es cuando brotan los no-objetualismos cuyo blanco de ataque es la fetichización del objeto [...] para ello tienen a disposición las ideas frías, el juego, el buen sentido del humor o los gritos expresionistas y pueden utilizar las galerías y museos o ir a la clandestinidad. Con el tiempo y a través de varias mediaciones, llegarán los efectos (no las obras) de los no-objetualismos (Acha 1984:224, 237-238).

${ }^{8}$ Momentos plásticos era el término, aún anclado a lo pictórico, con el que el grupo refería una práctica más bien performática. Luego la propia Maris Bustamante (2012) englobaría este tipo de prácticas dentro del término formas PIAS, que incluía la performance, la instalación y la ambientación.

${ }^{9}$ Esta situación no siempre es posible. Por ejemplo, Rubén Valencia murió en 1990 y Sol Henaro no tuvo oportunidad de entrevistarlo. Aprovecho este espacio para reconocer las reflexiones en torno del papel del artista realizadas en el curso La voz del artista. Metodología para la elaboración de una historia oral, que las maestras Pilar García y Tatiana Falcón impartieron en el posgrado en historia del arte de la UNAM de agosto a diciembre de 2014.

${ }^{10}$ La exposición La era de la discrepancia (Debroise y Medina 2006) planteó hace algunos años la problemática de las omisiones de representación en las colecciones y el desconocimiento de todo un periodo del arte mexicano reciente.
} 
no con la articulación y representatividad de sus colecciones, sino con el propio registro de su oferta cotidiana; la documentación de sus propuestas y la generación, a partir de los materiales resultantes, de archivos: los museos comisionan a los artistas obras de las que no siempre tienen registros uniformes. Pendientes - que también señalan el conservador del MUAC, la directora del LAA y quien tiene a su cuidado el centro de documentación, así como los artistas del dueto Pinto mi Raya, a cargo de un singular archivo-, cuestiones como el reconocimiento institucional de esta tarea y la generación de protocolos de documentación, pues en diversos espacios estas labores se realizan más por la iniciativa de algunas personas que por una estructura que tenga asignados recursos materiales, económicos y humanos para ellas. Así, en las siguientes líneas presentaré algunas experiencias e inquietudes, recabadas durante una serie de entrevistas realizadas en 2014, de distintos responsables de la tarea de la documentación y el manejo de archivos, no sin antes recuperar una consideración de la artista Mónica Mayer a propósito del valor de las documentaciones y la gestión de los archivos en un espacio como Ex Teresa Arte Actual, que desde 1994 abrió un sitio en el ámbito institucional — dentro del INBA- a la práctica de la performance:

[...] el archivo de un espacio de esta naturaleza es, en pocas palabras, el equivalente a la colección de pinturas de un museo. Además, resulta una herramienta fundamental para la comprensión de las propuestas: el arte sólo adquiere su verdadera dimensión cuando está contextualizado, cuando es posible entenderlo en su momento histórico, su contexto artístico y el proceso personal del artista. Para eso sirven las colecciones y los museos. Los artistas han aportado en esta empresa (Mayer 2006:10).

Mayer (2006:19) plantea en el mismo texto que Ex Teresa habría podido considerarse museo, y no centro cultural, de haberse cuidado la estructuración de su archivo documental, el cual habría fungido como su acervo museístico —como sucede en importantes instituciones de arte contemporáneo- desde que se iniciaron actividades. La observación resulta fundamental para reflexionar no sólo sobre la experiencia de Ex Teresa, sino sobre los diversos espacios que exhiben arte contemporáneo y trabajan de acuerdo con esquemas de comisiones, de los cuales resultan obras que no se integran a sus acervos en tanto obras, sino mediante documentaciones, en los que el reto de la documentación y de la gestión de los archivos adquiere gran relevancia.

Es el caso, también dentro de la estructura cultural pública, del LAA, que desde el año 2000 funge como un espacio para propuestas situadas en el cruce del arte y la tecnología. Como en términos administrativos no se lo juzga museo, carece de una colección propia. De esta manera, al trabajar con base en el citado esquema de comisión de obras, entre sus principales desafíos está la documentación y generación de un archivo de sus propuestas. En entrevista, la artista y curadora Tania Aedo se refiere a las políticas de documentación de las propuestas artísticas en el LAA, que ella encabeza:

De entrada, como en casi todos los museos, no hay un equipo conformado completo en el que puedas recargar a un área la parte de preservación, y lo que sucede en el LAA es que, como no es museo, no tiene esa partida asignada para preservación de su colección. Por eso trabajamos en el Centro de Documentación, porque nuestra riqueza es más un acervo documental (Aedo 2014).

Resulta interesante contrastar la experiencia de Claudio Hernández, quien, en su papel como jefe del Departamento de Restauración del MUAC, ${ }^{11}$ ha trabajado en colaboración con otras instancias del museo (como las colecciones de obras y de acervos documentales) para el desarrollo e implementación de modelos de documentación que involucran a los artistas. Refiere, asimismo, la permanencia de retos en esta práctica:

Primero nació el archivo (Centro de Documentación, Información e Investigación Arkheia); está el interés, pero necesita refinarse mucho más lo relacionado, lo que se produce, lo que se documenta. En este museo hay muchos proyectos documentados con Periscopio (un proyecto audiovisual de entrevistas con artistas), pero muchas exposiciones no lo están del todo. Nosotros tenemos un registro, Prensa, otro, pero no es lo mismo que decir que una obra estará en un catálogo, que exige otro tipo de registro. Es un problema que tenemos: están documentadas las colecciones, pero no en la calidad que se necesita (Hernández 2014).

También en entrevista, la artista Mónica Mayer considera los retos de Pinto mi Raya, un proyecto de largo aliento que ha consistido en la realización, junto con el artista Víctor Lerma, de un archivo que contiene obras propias, de otros artistas y, desde 1991, material hemerográfico. Con más de 250 mil textos sobre arte en su acervo, plantea que el tipo de investigación a la que se somete y las decisiones técnicas de conservación de los materiales deben valorarse puntualmente debido a la cantidad de recursos necesarios:

Tenemos que entender qué queremos y lo que se necesita. Luego tenemos que conseguir con quién hacerlo y que sea un trabajo que se patrocine. De gratis está imposible. Nuestro servicio hemerográfico funcionó siempre porque estaban suscritas bibliotecas. Fue un proyecto que salió muy bien porque estaba a disposición de otras personas y

\footnotetext{
${ }^{11}$ Aquí debe llamarse la atención sobre un hecho: contar con un conservador en el equipo no es una realidad de todos los museos en México.
} 
se iba pagando solo. Ya cambió el tiempo. No es lo mismo. Nos tocó el cambio de papel a digital. Aunque no es lo mismo: puedes recibir todos los periódicos digitales, pero otra cosa es guardar la información, catalogarla, archivarla y ordenarla [...]. Nosotros empezamos planteando que la parte de hemeroteca era como una pieza porque el proyecto de Pinto mi Raya es lubricar el sistema artístico. Dentro de ese contexto planteamos un trabajo práctico de carácter conceptual aplicado. Para nosotros era importante que se conformara este conjunto de información. Con el tiempo y las discusiones, y [entendiendo] cómo está el asunto para el arte efímero, empezamos a plantearnos el archivo como la obra misma. Con la discusión, vamos concibiendo nuestro trabajo de diferentes maneras (Mayer 2014).

Lo que de entrada demuestran las tres declaraciones previas es que cada archivo supone una lógica interna y problemas de configuración particulares, amén de que el reto que suponen en términos de conservación, así como en lo referente a la difusión sobre las prácticas artísticas que permiten realizar y su valor como puntos de partida para la investigación, no son comprensibles si se soslayan las vocaciones de las instituciones o los espacios que generan y alojan tales archivos. Entre el archivo como un problema institucional museístico y el archivo como obra de arte - y eso es lo que quiero demostrar en este ensayo- existen diferencias sustanciales.

Como referencia obligada sobre las implicaciones en la configuración de los archivos, vale regresar a las consideraciones de Jacques Derrida (1997): como ha formulado en distintos espacios, la cuestión de los archivos es una cuestión política por razón de que el archivo está en relación con el secreto: "no hay archivos sin un poder de capitalización o de monopolio, de cuasi monopolio, de agrupación de huellas estatutarias y reconocidas como huellas. Dicho de otro modo, no hay archivos sin poder político" (Derrida 2002:81-128).

En el contexto de la apertura al público de un archivo audiovisual, el autor sostuvo un diálogo en el que consideró que hay poder y jerarquía en manipular los elementos de un archivo y su configuración: el archivo, planteo, empieza donde la huella se organiza y selecciona; ésta y aquél se diferencian en virtud de la autoridad que determina al archivo, incluso en los más liberales y democráticos (Derrida 2002:95). De tal manera, no hay archivos sin destrucción, en tanto que se escoge lo que se conserva, esto es, siempre se selecciona, como siempre, se deja fuera. Así, pensar en las cualidades de la configuración y en las condiciones de existencia de los archivos en los museos no es un asunto menor. Así lo señala la propia Mayer (2006:19): un archivo habla más de sí por sus carencias que por lo que contiene y permite, asimismo, pensar de manera ampliada en las formas de existencia de las obras de arte. Como lo propone Gérard Genette (1997:16), teórico literario:
Las obras no tienen como único modo de existencia y de manifestación el hecho de "consistir" en un objeto. Tienen al menos otro, que es el de trascender esa "consistencia", ora porque "se encarnen" en varios objetos, ora porque su recepción pueda extenderse mucho más allå de la presencia de ese (o esos) objeto(s) y en cierto modo sobrevivir a su desaparición.

Luego, para utilizar sus términos, al permitir investigar, pero también recrear las obras, los archivos parecen operar en la tensión entre las formas de inmanencia (su estatuto ontológico) y de trascendencia (las relaciones estéticas que producen las obras). Precisa el autor: "no pretendo en modo alguno sugerir que las obras no consistan en nada, sino más bien que su existencia consiste en una inmanencia y una trascendencia. Me parece que muchas oscuridades, desacuerdos y a veces atolladeros teóricos se deben a una confusión muy extendida entre esos dos modos de existencia" (Genette 1997:16).

\section{Condiciones actuales}

En el contexto de la celebración del Día Internacional de los Museos en 2011, Pilar García ofreció en el MUAC la charla "Políticas de archivo y reactivación de memoria" (Gómez 2011), en la que se refirió al proyecto Arkheia del Centro de Documentación, Información e Investigación que encabeza desde 2008, año de fundación del museo, en la que compartió reflexiones sobre la conservación de documentos digitales y las distintas plataformas de los archivos, además de los retos que plantean de manera particular. García destacó como un logro la posibilidad de considerar Arkheia como patrimonio universitario integrado en relación con la colección artística del museo. Compartió, de esta manera, el mecanismo por el cual han afrontado, en términos de recursos económicos y humanos, los altos costos que suponen los archivos, es decir, cómo han trabajado proyectos específicos "para activar la memoria a partir de la invitación a especialistas para realizar exposiciones de los archivos, la apertura a investigadores y el establecimiento de redes con otros espacios museísticos para compartir información" (Gómez 2011).

Al respecto, en entrevista para la escritura de este ensayo, Mayer (2014) destaca el hecho de que Arkehia es el único espacio que ha conseguido proteger legalmente los archivos y conseguir recursos para conservarlos: "es un asunto de fondos y no sé qué tantos les dediquen, por ejemplo, en LAA y ExTeresa". Para Claudio Hernández, Arkheia da cuenta del hecho de que las instituciones han tomado conciencia del trabajo de los archivos, aunque — como se ha visto — hay temas que están por resolverse, el proyecto:

[...] es un gran ejemplo [...] que empezó de cero [...]. Pilar García ha estado al pendiente de conseguir recursos para la conservación y la digitalización. Me parece un buen 
ejemplo, pero en otras instituciones, aunque se ha avanzado y se han volteado a ver los archivos, no quiere decir que se hayan resuelto las problemáticas. Si ves las preguntas, ahí siguen abiertas (Hernández 2014).

Así se concibió el trabajo desde la fundación del espacio del MUAC, es decir, en claro diálogo con una tendencia internacional sobre la gestión de los archivos. En ese museo, como ha explicado Hernández, los distintos departamentos trabajan de manera conjunta, lo cual no sucede de igual forma en otros espacios, si bien se han realizado diferentes tipos de conceptualizaciones y materializaciones en un contexto en el que, al parecer, se inician tanto un gran interés por la apertura de centros de documentación como la presentación de exposiciones de archivo. El trabajo, como se ha adelantado, responde a las características de cada espacio.

Sobre la labor en el LAA, Tania Aedo (2014) reconoce el problema de los recursos económicos, afrontado mediante la investigación:

Una cosa que fue muy importante fue tomar la decisión de que, si no teníamos los recursos para hacer un proyecto de preservación con todas las características que un proyecto así requiere, lo que teníamos que hacer era invertirlo en un proyecto con una orientación más curatorial. De ahí surgió (Ready) media, ${ }^{12}$ integrado por una serie de videos y un libro. Para hacer los DVD invitamos a artistas y curadores, un equipo interdisciplinario, a que hicieran dos cosas: por un lado, una revisión, una lectura del archivo de 10 años y, por el otro, una recomendación de cómo complementarlo. Como esfuerzo de preservación, no estaría su riqueza técnicamente hablando sino más bien la parte curatorial. Claro que ahora está preservado el material, por ejemplo, en la Fonoteca Nacional, pero el aporte es mucho más curatorial. Lo mismo con el libro.

Esta declaración evidencia la profunda relación entre las condiciones materiales de los archivos y el papel central que cobran como punto de partida en las investigaciones en la historia del arte. Con base en las indagaciones que varios especialistas realizaron en el archivo del LAA, se formularon recomendaciones de adquisición de material complementario, esencialmente propuestas para circunstancias específicas que tienen que ver, más bien, con el reto de los recursos económicos y humanos. De acuerdo con Aedo (2014), al no tener condiciones para resguardar una colección propia, el LAA ha tenido que generar una suerte de práctica experimental dentro de la investi-

\footnotetext{
${ }^{12}$ Se refiere a la investigación coordinada por Karla Jasso y Daniel Garza-Usabiaga (2010:17-20), en cuya introducción ambos explican el corte historiográfico-arqueológico del proyecto, que busca "provocar futuras investigaciones que eviten el tedioso recurso de lo 'causal y lineal' y opten por la 'inventiva y la profundidad'".
}

gación. Por otra parte, en el día a día hay esfuerzos que se realizan gracias al interés de agentes específicos. Paola Gallardo, responsable de los servicios educativos en el LAA, se encuentra involucrada y comprometida con la generación de una documentación adecuada desde que se integró el equipo, en 2008. Sobre su labor explica:

Más que ningún espacio, nos enfrentamos a cuestiones
tecnológicas: mañana no sirve el monitor o ya no existe el
link del netart. Guardamos todo lo que aporte, documen-
tos que aporten el sentido museográfico y museológico.
Es un patrimonio intangible reciente. El espacio del centro
de documentación, abierto al público desde 2009, que-
dó superado desde 2012. [...] Desde la muestra de Tania
Candiani (2012), cada vez se hacen manuales más espe-
cíficos, trabajamos más de cerca con el Cencropam y se
hacen entrevistas de artistas. Tienes la pieza y la entrevista.
Por eso pienso que la imaginación es el primer paso para
la conservación. Imaginar implica pensar qué va a pasar
después (Gallardo 2014).

Llama la atención el carácter reciente de estos protocolos, que se han ido constituyendo en función de la práctica y el entusiasmo de personas específicas. Sin embargo, aunque estas acciones subsanan diversos problemas, al ser resultado de la voluntad de personas y no de medidas institucionales, no garantizan que estas tareas se lleven a cabo constantemente y a largo plazo. Mayer (2014) también ha hablado sobre la relación de los archivos con sus productores: narra que sus hijos bromean con quemar el archivo en el futuro; pensando en la posteridad, los hijos de Mayer y Víctor Lerma les han pedido tomar decisiones respecto del manejo de los documentos. Conservar un archivo de tales dimensiones impone un reto mayúsculo:

Por un lado, tenemos la suerte de tener espacio; si no, no habría archivo. Por otro, en la cuestión de conservarlo hasta ahora [también] hemos tenido suerte. Son 250000 las noticias de arte que tenemos y apenas a [uno de los paquetes correspondientes a] una quincena le salió un bicho. A uno solo. Ha sido poco el material que se ha echado a perder, pero a la larga constituye un reto mantenerlo. Por otro lado, hasta ahorita hay material, como el de crítica, que está muy bien organizado porque era un servicio que dábamos. [...Pero] lo de noticia, en 20 años nadie había venido a consultarlo, sino hasta ahora que hay un taller. Como no está catalogado, depende de nuestra memoria. Los catálogos no tienen orden. [...] hacer accesible [el material] es un reto (Mayer 2014).

Como lo muestran las distintas experiencias, si se carece de un respaldo institucional, el trabajo de los archivos se liga a la mera voluntad de las personas, además de que, sin criterios preestablecidos para su gestión, y sin los recursos necesarios, los problemas persistirán. 


\section{Los pendientes}

Los entrevistados citados hasta ahora plantean un panorama en el que se entrecruzan retos diversos, como la falta tanto de recursos (afrontada de maneras creativas) como de criterios institucionales de largo plazo. Desde mi punto de vista, en el establecimiento de tales criterios reside una vía para dar cara a los retos de la conformación de documentaciones adecuadas, la consecuente configuración de archivos y su utilización para la investigación y recreación de las obras. Para Hernández (2014) las dimensiones de los pendientes suponen, primeramente, tomar mejores decisiones; más aún, debe pensarse en estrategias concretas antes de tomarlas (no se puede digitalizar todo sin discriminar la relevancia de cada documento), trabajar por metas específicas y considerar el tiempo que cada una exige, así como sus beneficios. "Es un mundo, pero si lo vas seccionando, es más fácil pensar, ahora sí, en los respaldos y los servidores o cualquier otra estrategia de conservación de información digital a largo plazo. En mi tesis de licenciatura para la Escuela Nacional de Conservación, Restauración y Museografía, Instituto Nacional de Antropología e Historia (ENCRYMINAH) (Hernández 2005) mencionaba los discos duros y hoy eso está sobrepasado" (Hernández 2014); y, segundo, en virtud de que hay una dimensión que también se relaciona con las diferentes gestiones, debería trabajarse con políticas más concretas y de más largo aliento:

Se ha dado difusión [a los materiales de archivo], pero lo que nos interesa ver es cómo se están conservando. Por una parte está bien que se abran los archivos y se invite gente a revisarlos, pero ¿qué haces frente a lo que se ha perdido? ¿Qué estrategias tomar para que eso no vuelva a ocurrir o, al menos, saber qué se perdió? Saber exactamente qué hay. Es una tarea a medias. Hay una reflexión desde varios puntos de vista de activar, tal vez de conservar, pero [el tema] no está resuelto totalmente. Sí tiene que ser una visión desde la dirección. Dejar todo por escrito facilitaría mucho: que el archivo funcione de cierta manera, esté quien esté (Hernández 2014).

Para Aedo (2014) resulta positivo que la falta de recursos haya llevado a enfocar soluciones curatoriales y de investigación. De esta manera, cuando finalmente existan las condiciones institucionales y de recursos para la preservación, se tendrá más claridad sobre lo que debe preservarse. Mientras tanto, se han explorado enfoques de documentación creativos que involucran a los propios artistas, aunque, en el caso de espacios como el LAA, la especificidad técnica de las documentaciones implica un reto material mayor:

Seguimos con el mismo problema y, la verdad, creo que, además de [tenerlos] resguardados en los discos duros, lo que tratamos de hacer con los materiales es circularlos. Eso es lo primero, y hemos hecho uso de las redes sociales para esto. YouTube te sirve, por un lado, como un archivo y espacio de consulta, pero no lo es de ninguna manera. Puede desaparecer en cualquier momento. Para nosotros, el primer paso después de documentar es circular y que el público lo vea. Así, el archivo digital de la página del LAA corresponde a un esfuerzo de documentación y divulgación, pero en cuanto a preservación material, se producen los documentos pero no hay esta otra parte de preservación. Ahí el esfuerzo de documentación se guarda y todo, pero, la verdad, es material que sí está en riesgo (Aedo 2014).

Aunque ve el proceso con entusiasmo, Mayer (2014) advierte en la atención a la gestión de los archivos un trabajo que apenas comienza:

¿Qué falta? Falta todo: se empieza a hacer en el ENCRyM la maestría de conservación de arte efímero, ${ }^{13}$ que tendrá que ver mucho con archivo, naturalmente. Es un momento que empieza. Falta el empuje institucional. Falta que cambie lo legal y el presupuesto. El Fonca (Fondo Nacional para la Cultura y las Artes) le ha metido interés al archivo y a digitalizar. Las instituciones están en proceso de pensar cómo hacerlo bien. Luego lo hacen, pero no con el nivel profesional.

Además, sugiere, vale la pena observar cómo estos archivos tienen sentido a partir del diálogo con distintos departamentos de los museos, como el de los servicios educativos (Mayer 2014): en el LAA la responsable de esta área ha de ser la más activa en la documentación de las obras. También hace falta pensar, agrega, en los vínculos con los propios artistas, quienes también generan los suyos propios. El trabajo de los archivos supone la colaboración y el diálogo. Aedo (2014) menciona:

Tanto en los museos como en la vida real pasa lo mismo. Con (Ready) media nos dimos cuenta de que gran parte de los archivos audiovisuales, hablando de arte contemporáneo, los tienen los propios artistas; los generan y los cuidan. La preservación se vuelve una iniciativa de los propios artistas [...]. Por lo pronto, se está generando una red de intereses y mientras esa red siga viva hay [siquiera] la identificación de problemas comunes y necesidades en las instituciones. Lo que me está gustando más es que no es la documentación y la digitalización, sino que al mismo tiempo es la circulación y la relación directa con el público: patrimonio-público. Ponerlo en circulación, en cuestión y discusión.

Para la artista, los retos venideros sólo podrán resolverse con el diálogo:

\footnotetext{
${ }^{13}$ La artista se refiere a la maestría en conservación de acervos documentales, abierta en 2014 en la ENCRYM-INAH.
} 
En ese sentido, van a ser muy importantes los años que vienen. Hay una frase que dice Kenneth Goldsmith: "ustedes creen que internet va a estar ahí para siempre y la internet no va a estar ahí para siempre". La tratamos como si fuera eterna y no cambiara. Uno de los esfuerzos más importantes en esto es UbuWeb. ${ }^{14}$ Es el gran ejemplo: una persona sin un peso, con un archivo personal de arte contemporáneo como el que no se me ocurre otro. Y lo hizo una persona. Lo que le importa es que lo copies todo y lo uses. Si me preguntas en mi papel de funcionaria, te digo que es importante que continuemos con esta red para que un día existan desde los estándares hasta las facilidades para que todos los museos podamos digitalizar, documentar, sistematizar y poner en circulación nuestros acervos; pero si me lo preguntas como artista, investigadora, desde otro lugar te digo que lo que funciona es esto (Aedo 2014).

Ante los cuestionamientos sobre cómo tendría que ser el diálogo entre agentes privados, independientes, y artistas que piensan en su propia documentación, y de qué manera esto incidiría en la gestión de los archivos, Aedo (2014) se refiere a una realidad compartida. Desde su punto de vista, se trata de un momento en el que las distintas instituciones deben sensibilizarse sobre la materialidad de los documentos, pues, por un lado, se antoja lejano que el INBA o las instituciones públicas tengan las condiciones para asumir estos retos y, por el otro, acercarse a empresas que se encarguen de la tarea puede ser verdaderamente oneroso y ni siquiera resolver el problema. Como expuse al inicio de este apartado, Aedo coincide con los demás entrevistados en que afrontar los retos de manera creativa y compartida resulta una vía concreta ante la problemática que suponen los archivos, y, en otro aspecto, señala una realidad común en distintos espacios de exhibición que supone una discusión ineludible:

Una cosa muy práctica que sucede en el LAA y en todos lados: tienes un presupuesto y te lo vas a gastar antes en la exposición que en preservarla o documentarla. Objetivamente uno tendría que tener el dinero para producirla y el presupuesto para documentarla. Pero como no lo hay, entonces prefieres producir, y todos estamos así: produciendo, produciendo y produciendo y cuánto de lo que hemos hecho los últimos años se ha perdido ya. No digas "se va a perder", ya se perdió. Pero, ¿cómo debe ser esa conversación?: técnica, curatorial, de investigación y muy cercana a las vocaciones y misiones de los espacios; involucrar a los artistas, porque nos van ganando la batalla (Aedo 2014).

\footnotetext{
${ }^{14}$ Se refiere al portal [Ubu web (1996)], un proyecto del poeta conceptual Kenneth Goldsmith que contiene miles de entradas con obras de arte sonoro, poesía visual y videos. Trabaja de acuerdo con el esquema de contenidos libres.
}

Al respecto, para la artista es un buen signo el hecho de que la actual administración del Consejo Nacional para la Cultura y las Artes (Conaculta), a cargo de Rafael Tovar y de Teresa, tenga en su agenda la cultura digital y, por ende, se consideren como temas importantes los acervos, los archivos y la digitalización, lo que sin embargo no resuelve el problema: "nuestro patrimonio cultural ahora es en gran parte digital, con medios inestables, mucho más vulnerables que los anteriores" (Aedo 2014).

Las reflexiones citadas anteriormente establecen diálogos casi al pie de la letra con el planteamiento de la conservadora Morfín:

Los acervos de archivos y centros de documentación de estas instituciones se han conformado de manera aleatoria, y muchas veces sin seguir ningún tipo de estrategia; numerosos tipos de documentos, como registro de performance, acciones, instalaciones, obras en sitio específico, etc., se mezclan y almacenan indistintamente con dossiers de artistas, dibujos, esquemas, invitaciones. Es así [como], reunidos en libreros, archiveros o, incluso, dentro de cajas de cartón, reposan 3/4" U-matic, Beta, VHS, 8mm, 1/4", cintas de audio, audiocassettes, DAT, transparencias, CD, DVD, MiniDisc, etc., destinados a que las condiciones inapropiadas de manipulación y conservación, el vertiginoso avance de la tecnología y la (in)disponibilidad en el mercado de equipos reproductores, hardware y software, hagan de estas principales e imprescindibles fuentes de información para el estudio del arte contemporáneo materiales obsoletos e inaccesibles (Morfín 2009).

En suma, aunque hay esfuerzos significativos, persiste - como he venido insistiendo a lo largo de este ensayola problemática. Hay trabajo por hacer. Y, para Morfín (2009), es evidente que todos aquellos involucrados en la configuración, acceso, difusión y preservación del arte contemporáneo deben trabajar de manera conjunta en proyectos que aseguren a otras generaciones el acceso a este tipo de obras inestables.

\section{Conclusiones}

La dimensión material de las obras y sus documentaciones no es un asunto sólo de un departamento, como el de conservación —cuando éste existe-, dentro de los museos, sino involucra a varias de sus instancias. La complejidad y las implicaciones que tiene la generación de tales materiales exigen la aplicación de protocolos y políticas homologables, así como trascender más allá de las voluntades cambiantes en cada administración. Hay espacios que, al no ser considerados museos, no tienen posibilidad de generar una colección. Pero no sólo eso: sus estructuras orgánicas les impiden contar con recursos para determinadas actividades, como la documentación y conservación de los archivos. Como ha explicado Aedo, para los distintos espacios es evidente que se privi- 
legia la producción de una exposición por encima de la generación de una documentación.

Así, vale insistir en que si las prácticas artísticas y sus derroteros han trastocado la estructura de las colecciones de los museos, la generación de archivos debería estar en las agendas de las instituciones que alojan aquéllas, pues sus condiciones materiales suponen cambios en términos de gestión. Se trata de un asunto de la memoria y la escritura de la historia. Es decir, estas decisiones tienen implicaciones políticas.

Hasta ahora los esfuerzos realizados están anclados en buena medida a la buena voluntad de las personas que laboran en los museos, pero resulta necesario revisar la política de la generación y gestión de los archivos; esto es, se trata, más allá de retos técnicos en el trabajo cotidiano, de un problema de política cultural.

Si las documentaciones y los archivos que conforman permiten investigar, difundir y recrear las prácticas artísticas de nuestros días, la ausencia, deficiente integración e incierta conservación de aquéllos constituye desde ya un reto para la escritura de la historia del arte reciente. No es, pues, un problema solamente de los artistas, de los museos o de los conservadores, sino de las maneras en que las prácticas artísticas y las conversaciones que producen dan cuenta de su tiempo. Por esa razón sería una negligencia dejarlas perder.

\section{Referencias}

Acha, Juan

1984 "Por una nueva problemática artística en Latinoamérica", en Juan Acha (ed.), Ensayos y ponencias latinoamericanistas, Caracas, Galería de Arte Nacional (GAN), 224-238.

Aedo, Tania

2014 Comunicación personal, entrevista realizada a la directora del LAA-INBA, México, registro sonoro, 6 de mayo.

Arriola, Magalí y Peter Eleey (curadores)

2014 James Lee Byars. 1⁄2 An Autobiography, México, Fundación Jumex Arte Contemporáneo/MOMA PS1.

Bustamante, Maris

2012 Árbol genealógico de las formas PIAS, documento electrónico disponible en [https://marismariamagdalena.wordpress.com/2012/09/04/arbol-genealogico-de-las-formaspias-2/], consultado en septiembre de 2014.

Debord, Guy

1967 La Société du spectacle, París, Buchet Chastel.

Debroise, Olivier y Cuauhtémoc Medina

2006 La era de la discrepancia. Arte y cultura visual en México 1968-1997, México, MUCA-UNAM.

Derrida, Jacques

1997 Mal de archivo. Una impresión freudiana, Madrid, Trotta.

2002 "Huella y archivo, imagen y arte. Diálogo", en Artes de lo visible (1979-2004), Ponte Caldelas, Ellago, 79-128.
Gallardo, Paola

2014 Comunicación personal, entrevista realizada a la responsable del Departamento de Educación del LAA-INBA, México, registro sonoro, 6 de mayo.

Genette, Gérard

1997 La obra del arte I. Inmanencia y trascendencia, Barcelona, Lumen

Goldsmith, Kenneth

1996 UbuWeb, documento electrónico disponible en [http:// www.ubu.com], consultada en septiembre de 2014.

Gómez, Christian

2011 "El MUAC y la memoria activa", Cultura UNAM, 23 de mayo de 2011, documento electrónico disponible en [http:// www.cultura.unam.mx/index.html?tp=articulo\&id $=2611 \& \mathrm{ac}=$ mostrar\&ltemid $=207 \& \mathrm{ct}=322 \&$ titulo=el-muac-y-la-memoriaactiva], consultado en septiembre de 2014.

Gordon, Rebecca

2013 "Material significance in contemporary art", Art Matters. International Journal for Technical Art History, 5: 1-10.

Henaro, Sol

2011 No Grupo. Un zangoloteo al corsé artístico, catálogo de exposición, México, MAM-INBA.

Hernández, Claudio

2005 "Conservación del acervo documental del Laboratorio Arte Alameda", tesis de licenciatura en restauración de bienes muebles, México, ENCRyM-INAH.

2014 Comunicación personal, entrevista realizada al responsable del Departamento de Restauración del MUAC-UNAM, México, entrevista realizada en el MUAC, registro sonoro, 5 de mayo.

Jasso, Karla y Daniel Garza-Usabiaga 2010 (Ready) media. Hacia una arqueología de los medios y la invención en México, México, LAA-Centro de Documentación Príamo Lozada/ INBA-Conaculta.

Krauss, Rosalind E.

1996 "La escultura en el campo expandido", en Rosalind Krauss (ed.) La originalidad de la vanguardia y otros mitos modernos, Madrid, Alianza, 59-74.

Mayer, Mónica

2006 Escandalario. Los artistas y la distribución del arte, México, Fundación BBVA-Bancomer, ExTeresa/Fonca, Pinto mi Raya.

2014 Comunicación personal, entrevista realizada a la artista responsable, junto con Víctor Lerma, del proyecto Pinto mi Raya, México, registro sonoro, 7 de mayo.

Morfín, Jo Ana

2009 "Documentar, ipara qué?", La Pala, Revista Virtual de Arte Contemporáneo, documento electrónico disponible en [http://www.la-pala.com/articulos/item/172-documentar], consultado en mayo de 2014.

V2_lab

2003 Capturing Unstable Media, documento electrónico disponible en [http://v2.nl/archive/works/capturing-unstablemedia], consultado en marzo de 2015. 


\section{Síntesis curricular del/os autor/es}

\section{Christian Alberto Gómez Vega}

Facultad de Ciencias Políticas y Sociales (FCPyS),

Universidad Nacional Autónoma de México (UNAM), México

gomez.christian@outlook.com

Licenciado en ciencias de la comunicación (Facultad de Ciencias Políticas y Sociales [FCPyS], Universidad Nacional Autónoma de México [UNAM], México), donde se tituló con la tesis “El arte contemporáneo y sus mediaciones. El circuito del arte contemporáneo de la ciudad de México como espacio público de construcción de sentido" (2012). Participó en el libro El ámbito artístico y estético en la producción periodística y audiovisual (FCPyS-UNAM, México, 2013) con el artículo "La precisión en lo inasible: el problema de la escritura periodística sobre el arte contemporáneo". Ha sido profesor de las asignaturas Arte y Comunicación, Taller de Apreciación Estética y Narrativa de los Medios y Periodismo y Lenguaje Narrativo (FCPyS-UNAM, México). Forma parte del Seminario Arte y Materialidad, del posgrado en historia del arte (Facultad de Filosofía y Letras, UNAM, México), donde es estudiante de maestría.

Postulado/Submitted14.07.2014

Aceptado/Accepted 13.02.2015

Publicado/Published15.05.2015 